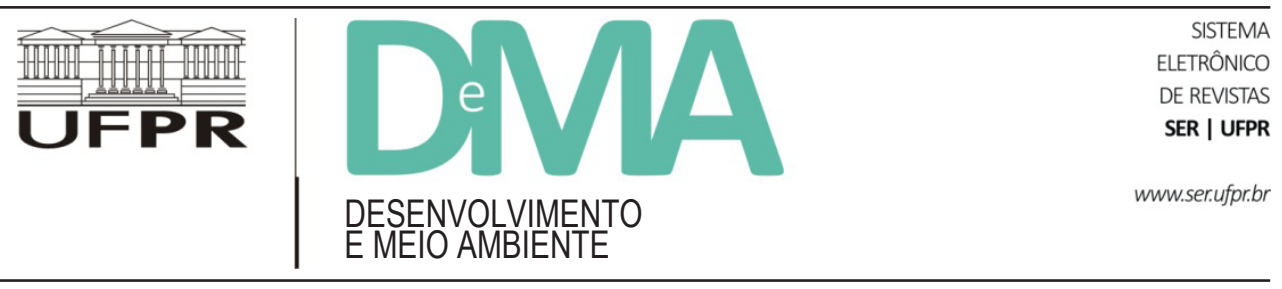

\title{
Sabedorias, cosmologias e estratégias de caçadores numa unidade de conservação da Amazônia
}

\section{Knowledges, Cosmologies and Strategies of Hunters in a Protected Area of The Amazon}

\author{
Rodrigo Augusto Alves de FIGUEIREDO ${ }^{1,2}$, Flávio Bezerra BARROS ${ }^{1 *}$ \\ ${ }^{1}$ Programa de Pós-Graduação em Agriculturas Amazônicas (PPGAA), Universidade Federal do Pará (UFPA), Belém, PA, Brasil. \\ ${ }^{2}$ Instituto Chico Mendes de Conservação da Biodiversidade (ICMBio), Belém, PA, Brasil. \\ *E-mail de contato: flaviobb@ufpa.br
}

Artigo recebido em 2 de outubro de 2015, versão final aceita em 20 de abril de 2016.

RESUMO: A partir de uma abordagem etnoecológica, estudamos os saberes, as cosmologias e as estratégias de caçadores sobre a fauna silvestre de importância alimentar. O estudo foi conduzido junto a uma comunidade quilombola da Reserva Extrativista Ipaú-Anilzinho, no Pará, Amazônia brasileira. Utilizamos os métodos da observação participante e entrevistas semiestruturadas como mecanismos para alcançarmos os resultados, os quais analisamos a partir das perspectivas qualitativa e quantitativa. Nosso estudo demonstra que os conhecimentos tradicionais acerca dos recursos cinegéticos são fundamentais na vida dos quilombolas, uma vez que se vinculam aos processos de reprodução material e simbólica. Tais conhecimentos acerca da caça são, portanto, mediados tanto por elementos de ordem prática como de ordem cosmológica, devendo ser reconhecidos como parte do patrimônio cultural. Devem ser igualmente valorizados nos esforços de conservação e manejo da sociobiodiversidade na unidade de conservação estudada, contribuindo para o envolvimento da comunidade nas estratégias de intervenção.

Palavras-chave: comida; quilombolas; caça; sociobiodiversidade; Amazônia.

ABSTRACT: From an ethnoecological approach we study the knowledge, cosmologies and strategies of the hunters about the wild fauna of feeding importance. The study was conducted next to a quilombola community of IpaúAnilzinho's Extractive Reserve, State of Pará, Brazilian Amazon. We use the methods of participant observation and semi-structured interviews as mechanisms to achieve the results, which were analyzed under qualitative and quantitative perspectives. Our study shows that traditional knowledge about hunting resources are essential in the life of quilombolas, since they are linked to processes of material and symbolic reproduction. Those knowledges about hunting are therefore mediated by both elements of practical and cosmological order, should be recognized as part of the cultural heritage. They should also be recognized in the conservation and management efforts of sociobiodiversity in the protected area studied, contributing to the involvement of the community in the strategies of intervention.

Keywords: food; quilombolas; hunting; sociobiodiversity; Amazon. 


\section{Introdução}

As relações entre os seres humanos e outros animais remontam aos primórdios da humanidade, pelas quais as sociedades pré-históricas conceberam a caça como importante fonte de alimentação para garantir sua sobrevivência (Ojasti, 2000). No meio rural, a fauna silvestre sempre ocupou lugar importante na cultura e na economia de diversos grupos humanos representados por povos e comunidades tradicionais, incluindo os povos indígenas, que se apropriam dos recursos naturais por um repertório de conhecimento ecológico que geralmente é local, coletivo, dinâmico e transmitido de geração a geração (Toledo \& Barrera-Bassols, 2009). O conhecimento ecológico tradicional (CET) é característico dos povos tradicionais e expressa um corpo cumulativo de saberes, compreensões, hábitos e crenças acerca das relações dos seres vivos (incluindo os humanos) entre si e destes com seus ambientes (Berkes, 1999).

A construção desse conhecimento se dá por meio das relações que cada grupo ou sociedade étnica estabelece com a natureza. Esse movimento de valorização dos conhecimentos dos povos tradicionais, desde que esses atores se libertaram da natureza e assumiram identidades coletivas, como afirma Almeida (2006), vem assumindo papel preponderante para uma discussão, a despeito da conservação e manejo da (socio)biodiversidade em todo o planeta.

No México, estudo realizado por Martinez-Ballesté et al. (2006) apontou a contribuição das práticas tradicionais do povo Maya no uso e no manejo de duas importantes espécies de palmeira (Sabal yapa e Sabal mexicana) para a economia local. Na China, Davies \& Wismer (2007) ressaltaram o papel dos conhecimentos sobre a natureza dos povos rurais no gerenciamento de práticas florestais, especialmente no manejo de recursos e suas implicações econômicas e sociais. No Brasil, Costa-Neto (2000) procurou registrar o conhecimento tradicional sobre a fauna cinegética de uma comunidade afro-brasileira, destacando a relevância desse conhecimento para a devida apropriação dos recursos, em particular em unidades de conservação. Estudos similares junto a outros grupos sociais podem ser observados em Marques (2001), Peloquin \& Berkes (2009), Pereira \& Schiavetti (2010), Barros (2012), Cajaiba et al. (2015) e outros.

Neste contexto, um dos recortes científicos pelo qual o conjunto complexo das interações que as culturas humanas mantêm com a natureza tem sido abordado a partir da Etnoecologia, campo de pesquisa interdisciplinar situado na interface entre as Ciências Sociais e Ciências Naturais, principalmente entre a Antropologia e a Ecologia, tendo como objetivo central compreender as formas como os povos percebem, concebem e conceituam os recursos, paisagens ou ecossistemas dos quais dependem para subsistir (Toledo \& Barrera-Bassols, 2009). Tal perspectiva propõe como foco de estudos a análise a partir da interação entre o sistema de crenças (kosmos), o conjunto de conhecimentos (corpus) e de práticas produtivas (práxis), considerando o contexto natural e cultural onde se desdobram. No entanto, outras definições teóricas e conceituais aproximadas para este campo do conhecimento têm sido propostas por diferentes autores (ver também Alves et al., 2010).

Na Amazônia, estudos de cunho etnoecológico com relação ao tema caça ainda são relativamente tímidos. Contudo, alguns esforços vêm contribuindo com abordagens sobre os conhecimentos e cosmologias de caçadores, como as investigações conduzidas, por exemplo, por Descola (1998), Fausto (2002), Viveiros de Castro (1996a; 1996b), 
Pezzuti (2003), Campos (2008), Azevedo \& Barros (2014). Esses estudos têm enfatizado cada vez mais a importância da Etnoecologia para a valorização dos saberes locais e uma gestão compartilhada dos recursos naturais. Nessa perspectiva, este trabalho objetiva apresentar o sistema de conhecimentos e estratégias envoltos na atividade de caça entre os quilombolas da RESEX Ipaú-Anilzinho. Neste texto, iremos privilegiar os elementos simbólicos acerca do uso dos recursos cinegéticos para fins alimentares.

\section{Area de estudo e a comunidade quilombola}

Realizamos este trabalho na comunidade quilombola de Joana Peres (4944'55.8'O, 0300'57.2"S), situada na Reserva Extrativista (RESEX) Ipaú-Anilzinho, uma unidade de conservação (UC) de uso sustentável localizada no município de Baião (Pará), criada por meio de Decreto Presidencial em 14 de junho de 2005, com o objetivo de proteger os recursos naturais e a cultura dos povos tradicionais residentes no território. $\mathrm{O}$ conceito de "RESEX" está ligado historicamente ao processo de formação de UC's no Brasil mediante as demandas do movimento de seringueiros e castanheiros amazônidas emergido na década de 1980, representado pelo líder Chico Mendes, em defesa da preservação da floresta e da manutenção dos modos de vida dos agentes sociais (ver também Allegretti, 1994).

Com 5.816,10 ha, a RESEX Ipaú-Anilzinho é delimitada pela margem esquerda do rio Tocantins, sentido Leste, e pela margem direita do rio Jacundá, sentido Oeste, apresentando uma diversidade de ambientes naturais que fomentam atividades socioeconômicas e culturais na região. A vegetação predominante é classificada como floresta densa de terra firme, com ocorrência frequente das es- pécies: castanha-do-Brasil (Bertholletia excelsa), bacuri (Platonia insignis), seringueira (Hevea brasiliensis), maçaranduba (Manikara amazonica) e mogno (Swietenia macrophilla). O clima é quente e úmido, com temperatura média anual de $26,3^{\circ} \mathrm{C}$ e índice pluviométrico variando entre $2.202 \mathrm{~mm}$ a $3.000 \mathrm{~mm}$ anuais. O período chuvoso, também chamado de inverno, estende-se entre os meses de dezembro e maio, e o período seco, ou verão, prolonga-se entre os meses de junho e novembro (CNPT/IBAMA, 2008).

A comunidade de Joana Peres compreende o maior núcleo populacional da Reserva, com cerca de 280 famílias que, na sua maioria, se autorreconhece como quilombolas. Essas famílias possuem uma economia baseada no extrativismo, na pesca artesanal, na agricultura e na criação de pequenos animais para o autoconsumo. A caça de animais silvestres é uma das práticas extrativistas que contribuem para a subsistência das famílias, estabelecendo importantes conexões na interface dos sistemas natural e cultural frente ao conhecimento tradicional.

\section{Procedimentos metodológicos}

Empreendemos a pesquisa entre janeiro e junho de 2014 a partir de uma abordagem etnoecológica (Marques, 2001; Toledo \& Barrera-Bassols, 2009) no intento de registrar os conhecimentos tradicionais, as cosmologias e as estratégias de que se valem os caçadores em suas atividades cotidianas. Nessa perspectiva, utilizamos a técnica da observação participante (Spradley, 1980), método de investigação que permitiu a convivência com a comunidade estudada e a inserção nas atividades de caça, e de entrevistas semiestruturadas (Huntington, 2000), por meio da aplicação de questionários 
predefinidos, que então possibilitaram direcionar o diálogo para as questões a serem investigadas. As entrevistas foram registradas por escrito e/ou com gravador.

Entrevistamos 34 caçadores apontados pelos próprios moradores da comunidade ou que se autorreconheceram como tais. Estes eram do sexo masculino e de idades que variaram de 15 a 65 anos. Dos 34 caçadores, selecionamos 10 para uma abordagem mais detalhada sobre os conhecimentos acerca da fauna cinegética, tais como: comportamento reprodutivo e social, hábitos alimentares, entre outros. Elaboramos uma lista dos animais caçados na região, cuja identificação dos nomes científicos das diversas espécies citadas se deu a partir da elaboração de registros fotográficos e das informações coletadas nas entrevistas sobre as características das espécies. Também contamos com o auxílio de taxonomistas para realizar essa identificação. Os nomes vernaculares das espécies, bem como as expressões e termos locais, foram mantidos a fim de registrar e valorizar a perspectiva do nativo.

Para cada caçador explicamos os propósitos da pesquisa, tendo sido solicitado Termo de Anuência Prévia (TAP) para a realização da mesma. Como a pesquisa envolve o acesso aos conhecimentos tradicionais associados à biodiversidade, os procedimentos éticos foram devidamente considerados, com o pedido de autorização junto ao Instituto Chico Mendes de Conservação da Biodiversidade (ICMBio) e ao Instituto do Patrimônio Histórico e Artístico Nacional (IPHAN), sob licenças no 418661 (ICMBio) e no 01450.004703/2014-85 (IPHAN). Estes procedimentos asseguram ao pesquisador os princípios do direito ligados à ética aplicada (Haldane, 2007) e à ética ambiental (Rolston, 2007).

\section{Resultados e discussão}

\subsection{O universo da caça}

A alimentação é o principal fundamento para a prática da caça de animais silvestres na comunidade quilombola de Joana Peres, tratando-se de uma forma de economia de subsistência, uma vez que visa atender às necessidades do caçador e sua família. Na época das cheias (dezembro a maio), quando há uma redução na oferta do pescado, a carne de caça desempenha um papel preponderante na dieta dos moradores. Caça-se em média de uma a três vezes por semana, dependendo da necessidade. Registramos 44 espécies cinegéticas utilizadas para alimentação, entre mamíferos, aves e répteis (Tabela 1). Essa diversidade de animais pode ser comparada aos padrões de caça de outras regiões estudadas no mundo por Pierret \& Dourojeanni (1967), Asibey (1974), Leopold (1977), Jorgenson (1995), Bolanos (2004) e, no Brasil, por Pereira \& Schiavetti (2010), Barros (2011), Cajaiba et al. (2015), entre outros.

Conforme observado, a caça é normalmente praticada pelos homens e quase nunca por mulheres, que por sua vez são responsáveis pelo preparo da carne para consumo. Há uma organização familiar do trabalho, na qual cada membro da família realiza uma função distinta. Alguns homens relataram que também sabem preparar a carne, mas preferem que as mulheres realizem tal função por elas terem um maior domínio e conhecimento culinário. Caçar exige, além de força e disposição, várias outras qualidades. Um bom caçador, por exemplo, precisa ter um conhecimento apurado sobre os animais: comportamentos, sons característicos, hábitos alimentares, locais que costumam frequentar, seus cheiros e modos de reprodução, como também sobre as estratégias e técnicas para rastejar, perseguir e acuar a caça. 
TABELA 1 - Espécies de caça utilizadas para alimentação na comunidade quilombola de Joana Peres, Reserva Extrativista Ipaú-Anilzinho, Amazônia brasileira.

\begin{tabular}{|c|c|c|c|}
\hline Nome local & Família & Nome científico & $\mathbf{N}^{0}$ de Citações \\
\hline \multicolumn{4}{|l|}{ MAMÍFEROS (27) } \\
\hline Anta & Tapiridae & Tapirus terrestris & 09 \\
\hline Caititu & Tayassuidae & Pecari tajacu & 15 \\
\hline Capivara & Hydrochoeridae & Hydrochaerus hydrochaeris & 17 \\
\hline Coamin/porco-espinho & Erethizontidae & Coendou prehensilis & 02 \\
\hline Cutia & Dasyproctidae & Dasyprocta leporina & 19 \\
\hline Lontra & Mustelidae & Lutra longicaudis & 02 \\
\hline Macaco cuxiú-preto & Pitheciidae & Chiropotes satanas & 02 \\
\hline Macaco guariba & Cebidae & Alouatta belzebul & 13 \\
\hline Macaco-da-noite & Aotidae & Aotus azarae & 01 \\
\hline Macaco-prego & Cebidae & Cebus apella & 04 \\
\hline Mucura & Didelphidae & Didelphis marsupialis & 03 \\
\hline Onça-pintada & Felidae & Panthera onca & 01 \\
\hline Paca & Dasyproctidae & Cuniculus paca & 31 \\
\hline Porco-do-mato/queixada & Tayassuidae & Tayassu pecari & 20 \\
\hline Preguiça bentinha & Bradypodidae & Bradypus tridactylus & 02 \\
\hline Preguiça branca & Bradypodidae & Bradypus variegatus & 02 \\
\hline Preguiça real/riá & Megalonychidae & Choloepus hoffmanni & 02 \\
\hline Quati & Procyonidae & Nasua nasua & 02 \\
\hline Tamanduá bandeira & Mymecophagidae & Myrmecophaga tridactyla & 02 \\
\hline Tatu rabo-de-couro & Dasypodidae & Cabassous unicinctus & 27 \\
\hline Tatu-bola & Dasypodidae & Tolypentis tricinctus & 02 \\
\hline Tatu-canastra & Dasypodidae & Priodontes maximus & 02 \\
\hline Tatu-de-quinze-quilos & Dasypodidae & Dasypus kappleri & 01 \\
\hline Tatu-peba & Dasypodidae & Euphractus sexcinctus & 01 \\
\hline Veado amarelo/branco & Cervidae & Ozotoceros bezoarticus & 10 \\
\hline Veado cariacu & Cervidae & Odocoileus virginianus & 03 \\
\hline Veado mateiro/vermelho & Cervidae & Mazama americana & 28 \\
\hline \multicolumn{4}{|l|}{ AVES (10) } \\
\hline Arara-vermelha & Psittacidae & Ara chloropterus & 02 \\
\hline Jaburu & Ciconiidae & Jabiru mycteria & 02 \\
\hline Jacamim-de-costas-verdes & Psophiidae & Psophiaviridis obscura & 02 \\
\hline Jacupemba & Cracidae & Penelope superciliaris & 04 \\
\hline Mutum-pinima & Cracidae & Crax fasciolata pinima & 01 \\
\hline Mutum-castanha & Cracidae & Pauxi tuberosa & 01 \\
\hline Nambu-galinha & Tinamidae & Tinamus guttatus & 03 \\
\hline Pato-do-mato & Anatidae & Cairina moschata & 03 \\
\hline Socó-boi & Ardeidae & Tigrisoma lineatum & 01 \\
\hline Saracura-do-brejo & Rallidae & Aramides cajaneus & 01 \\
\hline \multicolumn{4}{|l|}{ RÉPTEIS (7) } \\
\hline Calango jacuraru & Teiidae & Tupinambis teguixim & 02 \\
\hline Jabuti-amarelo & Testudinidae & Chelonoidis denticulata & 06 \\
\hline Jabuti-vermelho & Testudinidae & Chelonoidis carbonaria & 05 \\
\hline Jacaretinga & Alligatoridae & Caiman crocodilus & 03 \\
\hline Jacaré-açú & Alligatoridae & Melanosuchus niger & 02 \\
\hline Tracajá & Podocnemidae & Podocnemis unifilis & 05 \\
\hline Tartaruga-da-Amazônia & Podocnemidae & Podocnemis expansa & 06 \\
\hline
\end{tabular}

FONTE: Pesquisa de campo (2014). 
Os meninos quilombolas começam a caçar por volta dos doze anos, acompanhando os pais e irmãos mais velhos na mata e, assim, acumulando experiência pessoal. No entanto, um caçador somente é reconhecido como tal quando já caça sozinho, sabendo utilizar a arma empregada na caçada, principalmente a espingarda, e orientar-se na mata a partir da luz do sol ou pelos rios, igarapés e trilhas. A floresta de terra firme é o ambiente mais frequentado pelos caçadores, onde a ocorrência de uma diversidade relativamente grande de animais é comum.

O período chuvoso é considerado o mais propício para caçar, pois é quando amadurece a maior parte dos frutos nativos que servem de alimento aos animais e o chão da floresta encontra-se úmido, facilitando a identificação dos rastros deixados, além de abafar o ruído dos passos do caçador. No período seco (junho a novembro), a frequência da atividade é menor devido às dificuldades de encontrar os animais, pois há poucas frutas maduras para alimentá-los e tem-se uma maior oferta do pescado, que é o alimento mais consumido pelas famílias quilombolas nesse período. Alguns estudos desenvolvidos na Amazônia também identificaram o período chuvoso como a melhor época para a caça, destacando sua relevância para a subsistência das populações locais (Pezzuti, 2003; Almeida et. al., 2002).

As práticas de caça não possuem horários fixos, pois variam em consonância com os locais, as estratégias e técnicas utilizadas, que levam em conta os hábitos dos animais ou da espécie cobiçada, além da própria habilidade do caçador. Quando a caçada ocorre em horários nos quais predominam a luz do sol, o caçador geralmente procura caminhar em direção ao centro da mata (caçada a curso) até localizar a presa ou então esperá-la em locais específicos (caçada de espera), como as frutíferas. Quando a caçada é feita pela parte da noite, o caçador normalmente busca esperar a caça numa rede suspensa de um galho de árvore (caçada de tocaia) ou fazer a limpeza de uma trilha na mata - retirando folhas e galhos para diminuir o barulho - que geralmente os animais percorrem (varrida). No entanto, a lua e suas fases exercem grande influência sobre a atividade de caça, sendo considerada a "maré da caça".

Segundo os caçadores, os animais mudam a frequência e o horário em que se alimentam de acordo com a fase lunar. Nas fases de lua cheia, por exemplo, muitos animais de hábitos noturnos, como veado-mateiro (Mazama americana), tatu-peba (Euphractus sexcenctus) e paca (Cuniculus paca), costumam se refugiar ou sair de suas tocas para se alimentar no final da tarde, voltando antes da lua nascer. As fases de lua nova e crescente são consideradas as melhores para caçadas, pois é quando não está enluarado e eles se movimentam mais pela mata à procura de alimento ou para acasalar. Isso nos permite refletir que o conhecimento tradicional não é algo estático, sendo mediado pelas interações que o ser humano mantém com o ambiente no qual se encontra inserido e reinventado frente às transformações e necessidades impostas pela natureza (Posey, 1996), podendo, inclusive, variar qualitativa e quantitativamente, de acordo com o gênero, faixa etária e, até mesmo, nível de empatia com o animal (Ellen, 1998).

Quando se trata de caçada à noite, os quilombolas temem ser atacados pelo espírito de Anhanga, que ocupa um lugar central nas narrativas míticas locais relacionadas à caça. Anhanga é considerada uma figura maligna, que pode assumir a forma de diversos animais quando visível, mas o mais comum é a sua aparição na forma de um veado branco com olhos de fogo. $\mathrm{O}$ encontro com Anhanga pode fazer com que o caçador fique desorientado na mata 
e perca o caminho de volta ou, então, demore a encontrá-lo. Alguns dos entrevistados dizem que "não se pode meter no caminho da Anhanga, pois ela não deixa o caçador ter sossego" (Raimundo, 42 anos), "ela faz caminho igual caça e desarma as armadilhas. Onde ela está não passa caça alguma" (Josué, 27 anos). "Ela costuma assoviar e pisar em formato de caça para enganar o caçador. Não deixa animal nenhum passar na varrida" (Antônio, 60 anos).

É interessante notar que, ao escutar o assovio de Anhanga, o caçador deve regressar imediatamente da mata para evitar encontrá-la, desviando do seu objetivo inicial de caçar. Isso nos permite destacar os mitos como regras culturais (códigos de ética) que atuam no sentido de estabelecer limites e conduzir a ação social dos caçadores. A transgressão das regras culturais da caça pode provocar doenças espirituais (doenças de encante), cujos sintomas incluem a ocorrência de alucinações, fortes dores de cabeça e no corpo e estados febris, que devem ser tratados por meio de receitas ou rituais específicos. Na região amazônica, são bastante conhecidas as representações que certos animais possuem na reprodução da vida física e cultural das populações locais (Viveiros de Castro, 1996a; Descola, 1998; Lima, 2008; Barros, 2011).

$\mathrm{Na}$ abordagem de Lima (2008), as cobras são protagonistas dos mitos sobre a caça entre os Katukina de duas terras indígenas localizadas no Acre, que as cultuam como forma de acesso aos conhecimentos xamânicos e, ao mesmo tempo, temem matá-las ou maltratá-las para não correr o risco de ficarem expostos à sua vingança. Viveiros de Castro (1996a) argumentou que os animais são espíritos ("ex-humanos") que perderam os atributos herdados ou mantidos pelos humanos, desempenhando um papel simbólico e prático de destaque na cosmologia ameríndia. Descola (1998), não obstante, ressaltou que a relação com o animal na Amazônia indígena é fortemente influenciada por esquemas de comportamento enraizados nos sistemas cosmológicos, ontológicos e sociológicos característicos dessa área cultural. Barros (2011), estudando o sistema de caça entre os ribeirinhos do Riozinho do Anfrísio, no Pará, descreveu diversas situações em que caçadores foram castigados por seres sobrenaturais, "mães das matas", "curupiras", como consequência de abusos contra a caça ou mesmo lapsos cometidos, como, por exemplo, matar por engano uma fêmea grávida ou acompanhada de filhote. É preciso reconhecer, portanto, que a atividade de caça está inserida numa trama complexa de relações sociais e ecológicas que envolvem importantes elementos de ordem simbólica, onde o conhecimento tradicional encontra-se profundamente envolvido com outros conceitos socioculturais e cosmológicos.

Neste sentido, o êxito na caça entre os quilombolas não depende somente dos conhecimentos, estratégias ou habilidades pessoais do caçador. $\mathrm{O}$ caçador ou o seu cão que se dedica muitas horas procurando a caça sem encontrá-la pode estar "panema", termo local utilizado para designar aquele que é infeliz na caçada. Um caçador se torna panema quando uma mulher grávida ou menstruada da sua família consome carne de caça ou passa a mão sobre o seu ombro, ou ainda quando o sangue do animal que ele trouxe da mata entra em contato com as fezes, urina ou sangue humano. Além disso, o encontro com Anhanga pode causar "panemice", impedindo o caçador de voltar para casa feliz e satisfeito. O estado de panema é considerado uma moléstia e afeta não somente o caçador, mas também todo o grupo doméstico.

Nesse caso, o caçador tende a suspender suas caçadas até que se cure por meio de remédios ou banhos de ervas da mata. Uma receita comum entre os qui- 
lombolas para tirar panema é a defumação com folhas do pinhão-roxo (Jatropha gossypiifolia), comumente cultivado nos terreiros das casas, cumaru (Dipteryx odorata) ou paxiúba (Socratea exorrhiza), aplicada no caçador e em sua espingarda. Para cachorros com panema, pode-se esfregar a folha do jambu (Acmella oleracea) no seu focinho para abrir o faro novamente. A crença da panema é descrita entre outros povos da Amazônia por Galvão (1951), Da Matta (1977), Panzutti (1999), Barros (2012) e outros.

\subsection{Os conhecimentos tradicionais acerca da fauna silvestre}

A atividade de caça envolve um repertório de etnoconhecimentos que os caçadores quilombolas possuem e demonstram, em graus diversos, sobre os animais silvestres com os quais convivem e interagem diariamente. Esses conhecimentos, transmitidos pelos seus antepassados por meio da oralidade e reinventados pela observação e trocas de experiências cotidianas, estão relacionados principalmente com o comportamento alimentar e reprodutivo dos animais, servindo de base para a devida apropriação dos recursos. Dessa forma, os caçadores sabem onde, quando e como abater determinada espécie, otimizando o sucesso da caçada.

Sobre o comportamento alimentar, os caçadores conhecem bastante sobre a anatomia animal e os alimentos preferidos de cada espécie (Tabela 2). Podemos dizer que há uma forte conexão de saberes acumulados com a experimentação, pois os caçadores também conhecem os hábitos alimentares de uma determinada espécie por examinar os ingredientes encontrados no seu estômago. As informações teórico-práticas que os caçadores apresentaram sobre os hábitos alimentares dos animais oferecem um rico referencial para a definição de estratégias de manipulação da cadeia trófica, como o cultivo de determinadas espécies em roças e sítios e a utilização das frutíferas como atrativos de caça.

TABELA 2 - Principais alimentos das espécies de caça, segundo os caçadores de Joana Peres, RESEX Ipaú-Anilzinho.

\begin{tabular}{cl}
\hline Animal & Exemplo de alimento \\
\hline Anta & Folha de embaúba, Arumã \\
Caititu & Inajá e mandioca* \\
Capivara & Capim, canarana, marajazeiro, milho*, arroz* \\
Cutia & Tucumã, muruci, inajá, mandioca* \\
Guariba & Bacuri-tari, Abiorana, Inajá \\
Jabuti & Cajuaçu-vermelho \\
Mutum & Seringueira \\
Nambu & Bacuri-tari, mandioca* \\
Paca & Sapucaia, Inajá \\
Queixada & Come de tudo \\
Tartaruga & Palmito, fava, pataca \\
Tatu & Inajá, minhoca, cupim, insetos \\
Veado & Bacuri-tari, sapucaia \\
\hline
\end{tabular}

* Plantas cultivadas.

FONTE: Pesquisa de campo (2014).

O conhecimento envolvendo o comportamento social dos animais é apurado entre os caçadores, revelando que eles são observadores assíduos da fauna cinegética local. $\mathrm{O}$ caçador sabe como o animal faz para descansar ou fugir rapidamente ao perceber sua presença, fazendo uma previsão da reação desse animal, a escolha do horário e a elaboração da melhor estratégia para a prática da caça. Para as espécies que andam em bando, considerado aqueles grupos com cinco ou mais indivíduos, uma característica salientada é a existência de um "chefe" por bando, como é o caso das capivaras (Hydrochaerus hydrochaeris), porcos-do-mato (Tayassu pecari) e caititus (Pecari tajacu). Esse conhecimento mostrou-se similar àquele registrado na literatura por autores como Costa et al. (2002), Rufo (2012) e Garcia et al. (2009), respectivamente.

Destacamos trechos das narrativas relacionadas com o comportamento social de alguns animais de caça, de acordo com a percepção dos caçadores de Joana Peres: 
$O$ veado anda de madrugada e de dia ele fica mais na toca dele deitado. Geralmente de dia ele anda pouquinho. Ele pode estar na toca dele deitado, ele pode tá dormindo, mas o ouvido dele tá alerta, tá escutando tudo. Qualquer movimento que faça perto dele, ele pula da toca. Veado é um bicho muito arisco, assustado. Ele é muito rápido na perseguição. Só se escuta a carreira deles. Corre pela mata ou atravessa o rio, pois é ótimo nadador (José Maria, 43 anos).

A cutia é um bicho que não faz caminho, ela anda no caminho do outro e dá coincidência dela cair no caminho do caçador. Agora, ela tem um comportamento agressivo, ela morde (Vicente, 29 anos).

A capivara gosta de andar sempre em bando e é meio lenta. Sempre fica perto dos rios ou lagos, porque nada bem. É um bicho roedor e quando tá comendo a gente sente de longe. Ela é muito sutil quando sente que tem predador perto dela. É capaz de se movimentar que a gente não saiba a hora que ela saiu do lugar. Ela só se transforma em violenta se ela for agredida. Se ela não for agredida, ela não vem agredir ninguém. E se ela chegar a agredir alguém, sujeito a pessoa a levar fortes ferimentos (Raimundo, 59 anos).

Tatu no verão dá pra escutar o caminhar de longe na varrida, pois só anda de noite. É o bicho que mais demora a pegar, pois ele adora desviar o caminho (Manoel, 22 anos).

A diferença da guariba para outros macacos é que ela tem a hora de cantar. As guaribas cantam de manhã bem cedo, quando não é de tardinha. Elas gostam de comer bacuri-tari. Conforme elas vão comendo, também vai caindo na água. Aí, é como a gente acha elas também. Quando uma guariba dá contigo, ela se esconde. Ela sobe pra copa da árvore e fica quieta por detrás da folha, se escondendo (Antônio, 27 anos).

Já a preguiça é mansa, mais fácil de capturar, não foge como os outros animais. Só os machos costumam reagir. Tem que saber pegar (Josué, 32 anos).

Os caçadores também demonstraram ter um conhecimento profundo sobre o comportamento reprodutivo da fauna cinegética, apresentando informações relacionadas não somente aos modos e períodos reprodutivos dos animais, mas também aos comportamentos associados à reprodução, muitas das quais são semelhantes às referências da literatura acadêmica (Tabela 3). Sobre a capivara (Hydrochaerus hydrochaeris), por exemplo, afirma-

TABELA 3 - Conhecimentos referentes ao comportamento reprodutivo de espécies cinegéticas, segundo a percepção dos caçadores da comunidade de Joana Peres, Reserva Extrativista Ipaú-Anilzinho (Pará, Brasil) e a literatura acadêmica.

\begin{tabular}{|c|c|}
\hline Citações das entrevistas com os caçadores & Citações da literatura acadêmica \\
\hline $\begin{array}{l}\text { "Cutia tem no máximo três filhos por ano, de três em } \\
\text { três meses ela está de bucho". }\end{array}$ & $\begin{array}{l}\text { "Quanto aos aspectos reprodutivos, as cutias fêmeas parem de um a } \\
\text { dois filhotes por parto; o período de gestação médio é de } 117 \text { dias" } \\
\text { (Pinheiro et al., 1989). }\end{array}$ \\
\hline $\begin{array}{l}\text { "O caititu reproduz de um a quatro filhotes. Não tem } \\
\text { época certeira, é durante o ano todo. Depois de dois } \\
\text { meses a mãe não amamenta mais os filhotes". }\end{array}$ & $\begin{array}{l}\text { "Em condições naturais, a ninhada do Pecari tajacu varia de um } \\
\text { a quatro filhotes, ocorrendo sem época preferencial. O desmame } \\
\text { ocorre em torno de dois meses" (Garcia et al., 2009). }\end{array}$ \\
\hline 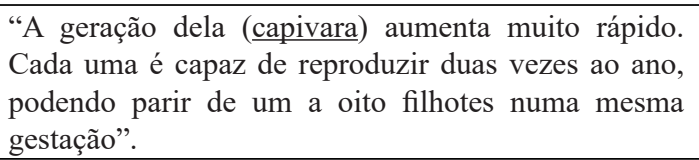 & $\begin{array}{l}\text { "Hydrochaerus hydrochaeris tem um ciclo de gestação de } 145 \text { a } \\
150 \text { dias, havendo a possibilidade de duas gestações por ano, com } \\
\text { média de quatro filhos em cada" (Costa et al, 2002). }\end{array}$ \\
\hline $\begin{array}{l}\text { "O tatu (referindo-se ao tatu-peba) põe muito filho, } \\
\text { de dois a quatro filhotes, principalmente na parte do } \\
\text { inverno, tempo chuvoso, que a gente vê a mãe com os } \\
\text { filhos. Ela chega a parir duas vezes no ano". }\end{array}$ & $\begin{array}{l}\text { "[...] com prole de um a três filhotes de sexos iguais ou diferentes, } \\
\text { de massa corpórea ente } 95 \text { a } 115 \text { g." (Gucwinska, 1971; apud } \\
\text { Medri, 2008). }\end{array}$ \\
\hline
\end{tabular}

FONTE: Pesquisa de campo (2014). 
ram que sua reprodução ocorre principalmente no período chuvoso (inverno), com a fêmea chegando a ter duas gestações por ano, variando de 1 a 8 filhotes cada, de ambos os sexos. A construção do ninho ocorre apenas perto do momento de parir, em um local isolado, e, assim que os filhotes nascem, a fêmea procura manter distância dos machos, que costumam ficar agressivos com os recém-nascidos, podendo, até mesmo, matá-los.

Aqui importa destacar que as informações apresentadas referem-se a breves aportes do conhecimento tradicional dos caçadores de Joana Peres, que, em geral, guardam muitas semelhanças com o conhecimento científico. O repertório desse conhecimento oriundo da relação dos caçadores com a fauna silvestre local pode ser essencialmente relevante para a conservação e o manejo da biodiversidade, como na perspectiva de Posey (1996), tendo em conta que pesquisas sobre caça ainda são incipientes na Amazônia, principalmente no contexto das UC's (Andriguetto-Filho et al., 1998). Este conjunto de conhecimentos é também a síntese histórica e cultural dos seus habitantes, codificada nos mitos, crenças e práticas, devendo ser reconhecido como elemento característico dos costumes da comunidade, contribuindo para o entendimento do homem como parte do mundo natural.

\subsection{As principais técnicas de caça dos quilombolas}

Toda técnica de caça, assim como os instrumentos a ela associados, está diretamente relacionada a um conhecimento prévio do caçador sobre a ecologia das espécies cobiçadas. Desse modo, diferentes técnicas são voltadas para a captura de determinadas espécies-alvo, com destaque para: i) espingarda, ii) cachorros, iii) zagaia, iv) arpão, v) tapuá, vi) arco e flecha, vii) tronco, viii) arapuca, ix) mundé, $x$ ) cacete e xi) coleta com as mãos (Tabela 4), muitas das quais são descritas entre outras populações da Amazônia por Pezzutti (2003), Almeida et al. (2006) e Silva (2012). Pudemos observar que a espingarda é a técnica mais utilizada pelos caçadores quilombolas e que cada uma das técnicas empregadas pode complementar-se entre si, dependendo da espécie e do local de ocorrência.

\section{Considerações finais}

A caça na comunidade quilombola de Joana Peres revelou-se uma atividade importante para a reprodução das famílias quilombolas, pois este recurso é fonte primordial de alimento, garantindo a segurança alimentar dos comunitários e a manutenção de suas tradições culturais. Essa relevância tem como referência os próprios conhecimentos ecológicos tradicionais apresentados pelos caçadores para a devida apropriação dos recursos. Essas sabedorias compartilham uma forma peculiar de visões de mundo, mediante as tradições, crenças e costumes locais, ligadas por um passado comum, demonstrando uma estreita relação sociedade e natureza nas práticas do dia a dia. Os saberes construídos, as cosmologias e as regras culturais conformam identidades no âmbito de um patrimônio cultural que deve ser valorizado e preservado em todos os aspectos pela gestão da Reserva Extrativista, tendo em conta que a manutenção dos modos de vida tradicionais constitui uma das suas finalidades.

Outro elemento-chave a ser mencionado é quanto ao preconceito que ainda existe em relação à prática da caça, constantemente enquadrada como uma atividade criminosa, uma vez que boa parte dos gestores de UC's e pesquisadores estritamente especializados desconhecem os outros elementos 
TABELA 4 - Descrição das principais técnicas de caça empregadas pelos caçadores quilombolas de Joana Peres, RESEX Ipaú-Anilzinho (Pará, Brasil).

\begin{tabular}{|c|c|c|}
\hline Técnicas de caça & Descrição & Espécies-alvo \\
\hline Espingarda & $\begin{array}{l}\text { Arma de fogo de cartucheira utilizada ao percorrer trilhas na mata ou } \\
\text { margear rios e igarapés à procura ou à espera da presa em árvores frutíferas. } \\
\text { Muitos caçadores costumam "envenenar" a espingarda, colocando pimenta } \\
\text { malagueta (Capsicum frutensens L.) na munição de chumbo. }\end{array}$ & Todos os tipos de mamíferos e aves. \\
\hline Cachorros & Procura ativa com auxílio de cães em trilhas na mata para rastrear a caça. & Mamíferos e répteis (jabutis). \\
\hline Zagaia & $\begin{array}{l}\text { Consiste de uma haste de aproximadamente } 2,5 \mathrm{~m} \text { de comprimento, } \\
\text { fabricada com madeira leve, possuindo uma superfície lisa. À extremidade } \\
\text { mais espessa da haste é fixado um tridente de ferro, com uma série de dentes } \\
\text { laterais, para segurar a presa. A mata de várzea é o melhor hábitat para a } \\
\text { caça de zagaia. }\end{array}$ & $\begin{array}{l}\text { Pequenos jacarés e tracajás } \\
\text { encontrados nas margens dos } \\
\text { igarapés, lagos e rios. }\end{array}$ \\
\hline Arpão & $\begin{array}{l}\text { Possui uma haste um pouco maior e mais pesada do que a zagaia, } \\
\text { feita especialmente com madeira de pracuúba e pau d'arco (Tabebuia } \\
\text { impetiginosa), com pontas farpadas e afiadas, de maior movimento e poder } \\
\text { de penetração. Ao visualizar a presa, o arpão é lançado e a presa fica presa } \\
\text { pelas pontas. É necessário rapidez no uso desta técnica. }\end{array}$ & $\begin{array}{l}\text { Serve para auxiliar na captura de } \\
\text { capivaras e jacarés em lagos ou } \\
\text { canais. }\end{array}$ \\
\hline Arco e flecha & $\begin{array}{l}\text { Arco de } 11 \text { palmos construído com madeira flexível, como paxiúba } \\
\text { (Socratea exorrhiza), pupunharana (Duckeodendron cestroides) e pau } \\
\text { d'arco (Tabebuia serratifolia), e um cordão para impulsionar a flecha. } \\
\text { A flecha consiste de uma haste feita da flecheira (Gynerium sagittatum), } \\
\text { contendo uma ponta de ferro amarrada fortemente com náilon em uma das } \\
\text { extremidades da haste. Também podem ser utilizados ossos de animais } \\
\text { como pontas, porém, hoje, é menos frequente. }\end{array}$ & Macacos guaribas e tracajás. \\
\hline Mundé & $\begin{array}{l}\text { Consiste de uma armadilha feita com um tronco pesado, que deve ser } \\
\text { inclinado sobre uma vara que o escora e funciona como desarme do tronco, } \\
\text { que então atingirá a presa quando aproximar-se da isca junto à vara, } \\
\text { ocasionando a morte do animal por esmagamento. }\end{array}$ & $\begin{array}{l}\text { Todos os tipos de animais, } \\
\text { dependendo do tamanho da } \\
\text { armadilha. Porém, é muito } \\
\text { empregado para a captura de tatus. }\end{array}$ \\
\hline Cacetes & $\begin{array}{l}\text { Pedaços de pau para o abate de animais acuados em buracos ou ocos de pau, } \\
\text { bem como aqueles encontrados na beira de rios ou igarapés. }\end{array}$ & $\begin{array}{l}\text { Mamíferos de pequeno porte, como } \\
\text { mucuras, e jacarés. }\end{array}$ \\
\hline $\begin{array}{l}\text { Coleta com as } \\
\text { mãos }\end{array}$ & Captura direta na água. & $\begin{array}{l}\text { Coleta de tracajás em praias ou em } \\
\text { locais rasos. }\end{array}$ \\
\hline
\end{tabular}

FONTE: Pesquisa de campo (2014). 
que permeiam a atividade de caça. Este estudo demonstra que, no caso específico, a caça é regida por regras altamente punitivas, pontuando que as comunidades conservam seus recursos não como uma ordem imposta, mas como um modo de vida em que as dimensões ecológicas, sociais e culturais se interconectam. Ressaltamos, contudo, que nem toda atividade de caça envolvendo povos tradicionais é sustentável, pois cada caso é um caso. Com efeito, defendemos que estudos interdisciplinares sejam valorizados a fim de elucidar outros processos que giram em torno desse tipo de atividade para não rotular a caça como um crime, como ocorre em boa parte dos casos. Lembramos que para muitas populações a caça constitui fonte primordial de proteína.

Nessa perspectiva, diversos estudos de cunho antropológico e etnográfico que enfocam o conhecimento ecológico tradicional têm enfatizado a importância do envolvimento de populações humanas nos esforços de conservação da biodiversidade (Posey, 1992; Balée, 1994; Viveiros de Castro, 1996a; Berkes, 1999; Costa-Neto, 2000; Folke, 2004; Barros, 2012; e outros). É partindo dessa perspectiva que os conhecimentos dos caçadores quilombolas de Joana Peres deveriam ser

\section{Referências}

Allegretti, M. H. Reservas extrativistas: parâmetros para uma política de desenvolvimento sustentável na Amazônia. O destino da floresta. Rio de Janeiro: Relume Dumará, 1994.

Almeida, M.; Cunha, M. C. Enciclopédia da Floresta: o Alto Juruá: práticas e conhecimento das populações. São Paulo: Companhia das Letras, 2002.

Almeida, A. W. B. de. Terras de Quilombos, Terras Indígenas, "Babaçuais Livres", "Castanhais do Povo", Faxinais e Fundos de Pasto: terras tradicionalmente ocupadas. Manaus: PPGSCA-UFAM, 2006. considerados no processo de elaboração de planos de manejo para a RESEX Ipaú-Anilzinho, uma vez que a mesma ainda encontra-se em fase de implementação. Como ressaltado por Hanazaki (2003), as RESEX's representam um dos exemplos mais claros de como o conhecimento ecológico local é importante para conservar áreas e recursos naturais e, ao mesmo tempo, assegurar os meios de produção e a economia das populações locais. Sem dúvida, o manejo adequado dos recursos naturais, aliado ao respeito ao conhecimento tradicional, fornece uma possibilidade para integrar a conservação da biodiversidade e o bem-estar dessas populações.

É relevante mencionar ainda que a realização de estudos etnoecológicos, no âmbito da caça, pode ter importantes implicações para o diálogo entre Estado e as comunidades locais na efetivação de estratégias conservacionistas, valorizando o manejo participativo e a cultura local. É nesse contexto que a Etnoecologia, dentro de uma perspectiva teórica e aplicada, contribui para o fortalecimento da gestão compartilhada da sociobiodiversidade, trazendo elementos para uma melhor compreensão da relação dos povos tradicionais com a natureza.

Alves, A. G. C.; Souto, F. J. B. Etnoecologia ou etnoecologias? Encarando a diversidade conceitual. In: Alves, A. G. C.; Souto, F. J. B. (Eds.). Etnoecologia em perspectiva: natureza, cultura e conservação. Recife: NUPEEA, 2010. p. 17-39.

Andriguetto-Filho, J. M.; Kruger, A. C.; Lange, M. B. R. Caça, biodiversidade e gestão ambiental na Área de Proteção Ambiental de Guaraqueçaba, Paraná, Brasil. Biotemas, 11(2), 133-156, 1998.

Asibey, E. O. A. Wildlife as a source of protein in Africa south of the Sahara. Biological Conservation, 6(1), 32-39, 1974. 
Azevedo, P. de A.; Barros, F. B. Comida, remédio, renda: conhecimentos e usos da mucura (Didelphis marsupialis) por comunidades ribeirinhas da várzea amazônica. Amazônica: Revista de Antropologia, 5(3), 862-878, 2014.

Balée, W. Footprints of the forest: Ka'apor ethnobotany. The historical ecology of plant utilization by an Amazonian people. New York: Columbia University Press, 1994. 416 p.

Barros, F. B. Biodiversidade, uso de recursos naturais e etnoconservação na Reserva Extrativista Riozinho do Anfrísio (Amazônia, Brasil). 232 p. Lisboa, Dissertação (Doutorado em Biologia da Conservação) - Universidade de Lisboa, Faculdade de Ciências, 2011.

Barros, F. B. Etnoecologia da pesca na Reserva Extrativista Riozinho do Anfrísio, Terra do Meio, Amazônia, Brasil. Amazônica: Revista de Antropologia, 4(2), 286-312, 2012.

Berkes, F. Sacred ecology: traditional ecological knowledge and resource management. Philadelphia: Taylor \& Francis, 1999.

Bolanos, J. E. Subsistence hunting by three ethnic groups of the Lacandon Forest, Mexico. Journal of Ethnobiology, 24(2), 233-253, 2004.

Cajaiba, R. L.; Silva, W. B.; Piovesan, P. R. R. Animais silvestres utilizados como recurso alimentar em assentamentos rurais no município de Uruará, Pará, Brasil. Desenvolvimento e Meio Ambiente, 34, 157-168, 2015.

Campos, M. A. A. Cruzando ecologias com os caçadores do Rio Cuieiras: saberes e estratégias de caça no Baixo Rio Negro, Amazonas. 111 p. Manaus, Dissertação (Mestrado em Biologia Tropical e Recursos Naturais) - UFAM, 2008.

CNPT/IBAMA. Laudo biológico da área de Ipaú e Anilzinho. In: Plano de manejo participativo da Reserva Extrativista Ipaú-Anilzinho (não publicado). MMA/ICMBio/ DIUSP, 2008.

Costa, D. S.; Paula, T. A. R.; Fonseca, C. C.; Neves, M. T. D. Reprodução de capivaras. Arquivos de ciências veterinárias e zoologia da UNIPAR, 5(1), 111-118, 2002.

Costa-Neto, E. M. Conhecimento e usos tradicionais de recursos faunísticos por uma comunidade afro-brasileira. Resultados preliminares. Interciencia, 25(9), 423-431, 2000.

Da Matta, R. "Panema": uma tentativa de análise estrutural. In: Da Matta, R. Ensaios de Antropologia Estrutural: o carnaval como um rito de passagem. Petrópolis: Vozes, 1977.
Davies, E. G. R; Wismer, S. K. Sustainable forestry and local people: The case of Hainan's Li minority. Human Ecology, 35(4), 415-426, 2007.

Descola, P. Estrutura ou sentimento: a relação com o animal na Amazônia. Mana, 4(1), 23-45, 1998.

Ellen, R. F. Indigenous Knowledge of the Rainforest. In: Maloney, B. K. (Ed.). Human activities and the tropical rainforest. Springer Netherlands: Kluwer Academic Publishers, 1998. p. 87-99.

Fausto, C. Banquete de gente: comensalidade e canibalismo na Amazônia. Mana, 8(2), 7-44, 2002.

Folke, C. Traditional knowledge in social-ecological systems [editorial]. Ecology and Society, 9(3), 7, 2004.

Galvão, E. Panema: uma crença do caboclo amazônico. Revista do Museu Paulista, 5, 221-225, 1951.

Garcia, A. R.; Kahwage, P. R.; Ohaschi, O. M. Aspectos reprodutivos de caititus (Tayassu tajacu). Revista Brasileira de Reprodução Animal, 33(2), 71-81, 2009.

Haldane, J. Ética aplicada. In: Bunnin, N.; Tsui-James E. P. (Orgs.). Compêndio de Filosofia. São Paulo: Edições Loyola, 2007. p. 529-358.

Hanazaki, N. Comunidades, conservação e manejo: o papel do conhecimento ecológico local. Biotemas, 16(1), 23-47, 2003.

Huntington, H. P. Using traditional ecological knowledge in science: methods and applications. Ecological Applications, 10(5), 1270-1274, 2000.

Jorgenson, J. P. Maya subsistence hunters in Quintana Roo, Mexico. Oryx, 29(1), 49-57, 1995.

Leopold, S. Fauna silvestre de México: aves y mamíferos de caza. Instituto Mexicano de Recursos Naturales Renovables, 1977.

Lima, E. C. de. Cobras, xamãs e caçadores entre os Katukina (pano). Tellus, 8(15), 35-57, 2008.

Marques, J. G. W. Pescando pescadores: ciência e etnociência em uma perspectiva ecológica. São Paulo: NUPAUB/ USP, 2001.

Martínez-Ballesté, A.; Martorell, C.; Caballero, J. Cultural or ecological sustainability? The effect of cultural change on Sabal palm management among the lowland Maya of Mexico. Ecology and Society, 11(2), 27, 2006. 
Medri, I. M. Ecologia e história natural do tatu-peba Euphractuss excinctus (Linnaeus, 1758), no pantanal de Nhecolândia, Mato Grosso do Sul. 187 p. Brasília, Tese (Dourado em Ecologia) - Universidade de Brasília, 2008.

Ojasti, J. Manejo de fauna silvestre neotropical. Washington, DC: Smithsonian Institution/Man and Biosphere Program, 2000.

Panzutti, N. M. Impureza e perigo para povos de floresta. Ambiente \& Sociedade, 5, 69-77, 1999.

Peloquin, C.; Berkes, F. Local knowledge, subsistence harvests, and social-ecological complexity. In: Bay, J. Human Ecology, 37(5), 533-545, 2009.

Pereira, J. P. R.; Schiavetti, A. Conhecimentos e usos da fauna cinegética pelos caçadores indígenas "Tupinambá de Olivença” (Bahia). Biota Neotropica, 10(1), 175-183, 2010.

Pezzuti, J. C. B. Ecologia e etnoecologia de quelonios no Parque Nacional do Jaú, Amazonas, Brasil. 149 p. Campinas, Tese (Doutorado em Ecologia) - Universidade de Campinas, 2003.

Pierret, P. V.; Dourojeanni, M. J. Importancia de la caza para alimentación humana en el curso inferior del río Ucayali, Perú. Revista Forestal del Perú, 1, 10-21, 1967.

Posey, D. A. Traditional knowledge, conservation, and 'the rain forest harvest'. Sustainable harvest and marketing of rain forest products. Washington, DC, USA: Island Press, 1992. p. 46-50.
Posey, D. A. Os povos tradicionais e a conservação da biodiversidade. In: Pavan, C. (Org.). Uma estratégia latino-americana para a Amazônia. São Paulo: Memorial, 1996. p. 149-157.

Rolston, H. Ética Ambiental. In: Bunnin, N.; Tsui-James, E. P. (Orgs.). Compêndio de Filosofia. São Paulo: Edições Loyola, 2007. p. 557-571.

Rufo, D. A. Parentesco e diferenciação genética em queixadas (Tayassu pecari) do Pantanal Mato-grossense (MS). 58 p. São Paulo, Tese (Doutorado) - Universidade de São Paulo, 2012.

Silva, C. E. A caça entre os Asuriní do Tocantins: características e sustentabilidade. In: Cabral, A. S. A. C. (Org.). Contribuições para o inventário da língua Asuriní do Tocantins. Brasília: Laboratório de Línguas Indígenas/UnB, 2012.

Spradley, J. P. Participant observation. New York: Holt, Rinehart and Winston Ed., 1980.

Toledo, V. M.; Barrera-Bassols, N. A etnoecologia: uma ciência pós-normal que estuda as sabedorias tradicionais. Desenvolvimento e Meio Ambiente, 20, 31-45, 2009.

Viveiros de Castro, E. Os pronomes cosmológicos e o perspectivismo ameríndio. Mana, 2(2), 115-144, 1996 a.

Viveiros de Castro, E. Images of nature and society in Amazonian ethnology. Annual Review of Anthropology, 179-200, 1996b. 


\section{Apêndice 1: Registro fotográfico}
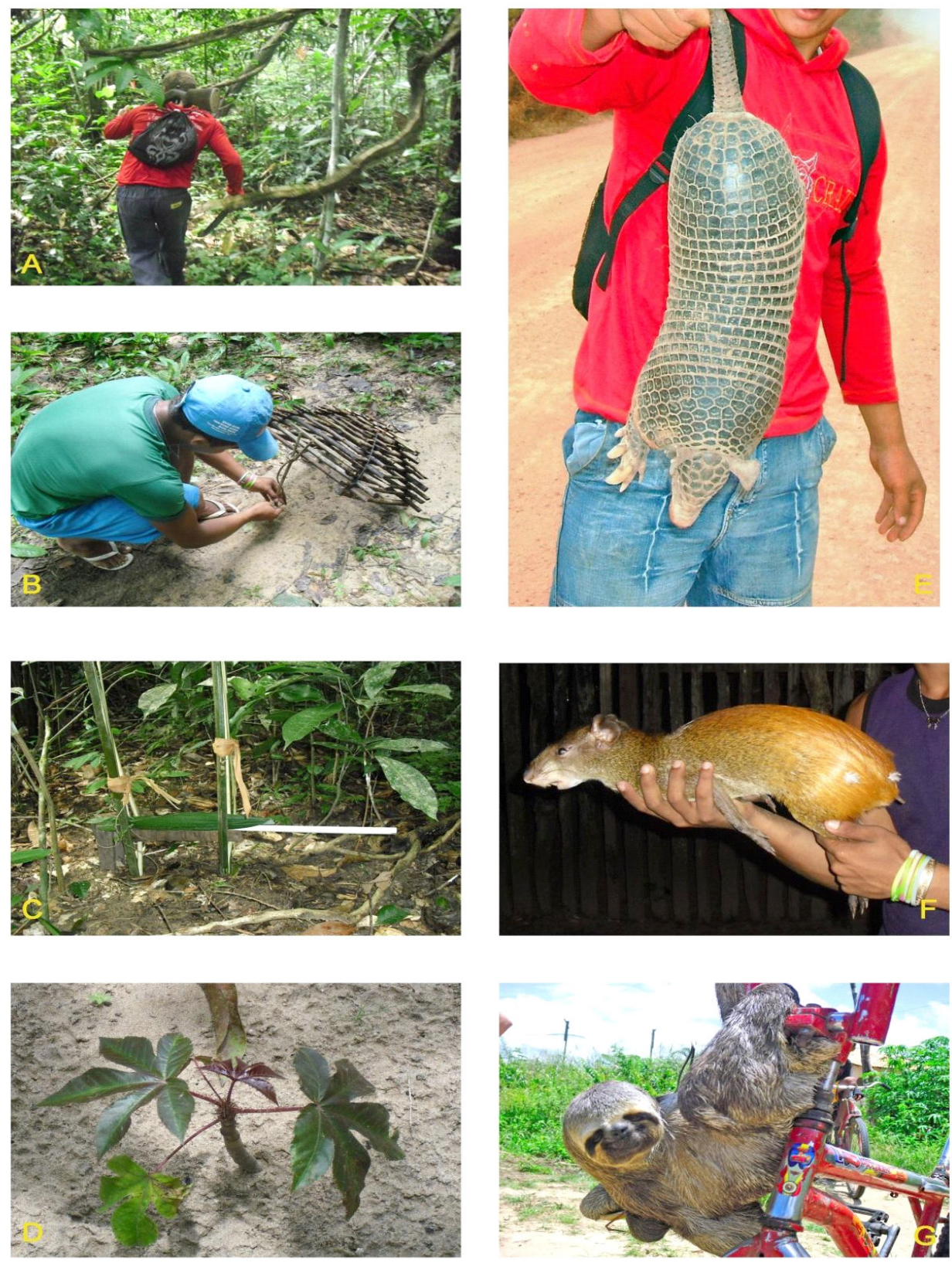

A) Caçador na mata com facão e espingarda; B) Arapuca sendo montada; C) Tronco armado; D) Pinhão-roxo (Jatrophagos sypiifolia) para curar panema; E-F-G) Animais caçados (de cima para baixo): Tatu rabo-de-couro (Cabassous unicinctus); Cutia (Dasyprocta leporina); e Preguiça-branca (Bradypus variegatus). Fotos: Rodrigo Figueiredo. 